\title{
Pengembangan Desain Perencanaan Sistem Informasi Geografis sebagai Alternatif Pembelajaran dalam Keperawatan Kesehatan Komunitas
}

\author{
Nur Setiawati Dewi ${ }^{1, *}$, Artika Nurrahima ${ }^{1}$, Panji Wisnu Wirawan ${ }^{2}$ \\ ${ }^{1}$ Departemen Ilmu Keperawatan Fakultas Kedokteran, Universitas Diponegoro, Semarang, Indonesia \\ ${ }^{2}$ Jurusan Teknik Informatika, Fakultas Sains dan Matematika, Universitas Diponegoro, Semarang, Indonesia \\ nurse.tiawatidewi@fk.undip.ac.id
}

\begin{abstract}
Introduction: The learning process of nursing students faced complexity problems, particularly in community health nursing course. There is no latest information technology application that addresses are impacted to the educational problems of undergraduate and professional nursing program. An unclearly visualization of the data assessment of community nursing care provide distresses for lecturer and nursing student. Geographic Information Systems (GIS) provide a detail visualization that related to health problems in the community. This study aims to provide a visualization about the development of GIS that may become an alternative learning for nursing students.

Methods: This article describes the part of action research process. Five nursing students and two lecturers of community health nursing were recruited. The data collection was conducted by interview and observation for data assessment in the first step of development of GIS application.

Results: There were four steps of making of GIS application, which is divided into four steps, including need analyzing, application design planning, the diagram of data flow, and application description.

Conclusion: The GIS has benefit for learning process, some policies are necessary to mediate the development and application of GIS for nursing students in community health nursing course.
\end{abstract}

Keywords: Community health nursing, GIS, Nursing student

\begin{abstract}
Abstrak
Pendahuluan: Permasalahan dalam Proses Belajar Mengajar (PBM) pada mata kuliah keperawatan kesehatan komunitas sangatlah kompleks. Tidak adanya penerapan teknologi informasi terkini menyebabkan munculnya beberapa permasalahan pada jenjang pendidikan sarjana dan profesi. Ketidakjelasan visualisasi hasil pengkajian keperawatan memberikan kesulitan bagi dosen dan mahasiswa. Sistem Informasi Geografis (SIG) menjadi salah satu teknologi alternatif yang dapat memberikan visualisasi yang sangat detail terkait masalah kesehatan yang terjadi di masyarakat. Penelitian ini mempunyai tujuan untuk memberikan gambaran secara visual tentang bagaimana pengembangan SIG yang dapat digunakan sebagai pendekatan alternatif dalam pembelajaran bagi mahasiswa keperawatan di kelas.

Metode: Artikel ini merupakan bagian dari action research yaitu fase pengembangan aplikasi SIG. Lima mahasiswa dan dua dosen keperawatan komunitas juga direkrut sebagai partisipan. Wawancara dan observasi digunakan untuk mendapatkan data. Fase ini terbagi dalam empat tahapan yaitu analisis kebutuhan, perencanaan desain aplikasi, diagram alir data dan gambaran aplikasi.
\end{abstract}


Kesimpulan: Aplikasi SIG sangat bermanfaat sebagai penujang proses PBM, sehingga diperlukan suatu kebijakan dari institusi dalam upaya pengembangan dan penerapan SIG pada pembelajaran mata ajar keperawatan komunitas bagi mahasiswa keperawatan.

Kata kunci: Keperawatan kesehatan komunitas, Mahasiswa keperawatan, SIG.

\section{PENDAHULUAN}

Beberapa studi di negara maju menunjukkan bahwa aplikasi SIG telah diterapkan di rung lingkup kesehatan. Aplikasi SIG dalam bentuk penyimpanan data, analisis dan evaluasi untuk mendukung pengawasan dan pemantauan wabah penyakit. SIG dapat mengumpulkan data termasuk wilayah geografis epidemi penyakit insiden, data epidemi dan statistik, pasien yang memiliki penyakit epidemi di rumah sakit/masyarakat, spesies bakteri yang berbeda di setiap daerah, daerah berisiko tinggi dan zona pengawasan yang harus menghilangkan sumber penyakit, dan lainnya (Laosuwan, 2012); mortalitas penyakit jantung dan akses ke rumah sakit (Yamashita \& Kunkel, 2010); obesitas dan gerai makanan cepat saji (Li, Harmer, Kardinal, Bosworth, \& Johnson-Shelton, 2009).

Beberapa literatur keperawatan menyebutkan tentang pemanfaatan SIG sebagai teknologi untuk merekam semua data terkait profesi keperawatan dan masalah kesehatan yang menjadi ruang lingkup keperawatan. Namun penelitian terkait penggunaan SIG penerapannya masih sebatas pada setting praktik pelayanan keperawatan baik di rumah sakit ataupun komunitas. Courtney (2005) menyelidiki tentang distribusi tenaga keperawatan di Missouri sebagai evaluasi rekrutmen keperawatan; Caley (2004) menggambarkan pendekatan SIG untuk jaringan komunitas sebagai upaya pemberdayaan masyarakat dalam pencegahan bayi Berat Badan Lahir Rendah (BBR). Sedangkan penggunaan
SIG di bidang pendidikan dan pengajaran pada mahasiswa keperawatan masih sebatas kajian literature review (Andrew, 2006; Faruque, Hewlett, Wyatt, Wilson, Lofton, et.al, 2004) sehingga diperlukan eksplorasi lebih lanjut melalui penelitianpenelitian keperawatan. Padahal kemampuan yang mumpuni dalam teknologi informasi harus dimiliki dan diasah sedini mungkin, sehingga, mahasiswa dapat mengikuti perkembangan SIG secara lebih baik saat terjun sebagai perawat lapangan.

Hasil wawancara terhadap mahasiswa menunjukkan gambaran tentang harapan pada mahasiswa terkait penggunaan teknologi yang up to date dalam proses pembelajaran. Tidak ada visualisasi data yang baik dan jelas setelah melakukan tabulasi data sering mengakibatkan mahasiswa kesulitan dalam memahami dan menerapkan asuhan keperawatan komunitas. Pada jenjang mahasiswa profesi, dosen mengungkapkan permasalahan yang ditemukan di masyarakat seringkali tidak terintervensi secara tuntas oleh mahasiswa profesi karena ketidakakuratan data pengkajian dan pengulangan pengkajian pada subjek yang sama.

Berdasarkan hasil dari identifikasi permasalahan yang muncul pada mahasiwa, maka peneliti mencoba mengembangkan SIG sebagai alternatif pemecahan masalah yang muncul dalam proses belajar mengajar khususnya mata kuliah keperawatan komunitas baik pada jenjang sarjana maupun profesi. 


\section{METODE}

Penelitian ini mendeskripsikan salah satu tahapan dari penelitian action research yang dilakukan peneliti yaitu fase pengembangan aplikasi SIG. Pengembangan aplikasi ini menggunakan Kelurahan X sebagai area penelitian. Area ini digunakan karena merupakan wilayah binaan Departemen Ilmu Keperawatan Fakultas Kedokteran, Universitas Diponegoro. Salah satu aspek yang ditekankan dalam setiap pembelajaran praktik keperawatan komunitas adalah kemampuan mahasiswa dalam melakukan proses pengkajian terkait faktor-faktor yang berkontribusi terhadap masalah kesehatan di masyarakat khususnya pada penelitian ini adalah kejadian hipertensi dengan menggunakan model PRECEDEPROCEED sebagai dasar pemodelan dalam aplikasi SIG (Green \& Kreuter, 1991). Hal ini tentunya didukung dengan penggunaan metode pengambilan data yang tepat saat melakukan proses pengkajian.

Data primer dalam penelitian ini berasal dari lima mahasiswa keperawatan dengan menggunakan teknik wawancara terhadap responden. Selain itu, dua dosen keperawatan komunitas juga direkrut sebagai partisipan sekunder.

Tahap pertama dari penelitian ini adalah mengidentifikasi dan menganalisis kebutuhan mahasiwa keperawatan dan dosen keperawatan komunitas terkait pelaksanaan asuhan keperawatan dan kendala yang muncul selama proses berlangsung. Selain itu observasi juga dilakukan sebagai metode untuk mengobservasi aktivitas pendokumentasian asuhan keperawatan yang berasal dari mahasiswa selama kurun waktu tiga tahun terakhir. Tahap ini sebagai dasar acuan dalam mengembangkan kerangka dalam pengembangan SIG. Setelah diketahui secara jelas kebutuhan yang diharapkan maka mulai dilakukan tahap perencanaan desain aplikasi dilanjutkan dengan tahap pembuatan diagram alir data. Langkah selanjutnya adalah tahap pengembangan aplikasi SIG.

\section{HASIL}

\section{A. Analisis Kebutuhan}

Tahap pertama dari penelitian yang dilakukan adalah mengidentifikasi permasalahan dan kebutuhan mahasiswa dan dosen terkait analisis asuhan keperawatan komunitas manual yang telah dibuat, kendala dan harapan baik dari dosen dan mahasiswa.

Hasil wawancara terkait analisis kebutuhan mahasiswa dan dosen didapatkan hasil antara lain perlunya sistem yang mampu menyimpan secara aman semua data yang didapatkan dari setiap angkatan mahasiswa. Dosen mengungkapkan permasalahan yang ditemukan di masyarakat seringkali tidak terintervensi secara tuntas oleh mahasiswa profesi karena ketidakakuratan dalam data pengkajian dan pengulangan pengkajian pada subjek yang sama. Selain itu, dalam proses PBM mahasiswa tingkat sarjana didapatkan adanya kesulitan mahasiswa dalam visualisasi data selama proses pengkajian, sehingga mahasiswa menghadapi tantangan saat mengembangkan asuhan keperawatan komunitas.

Hasil observasi menunjukkan tidak adanya sistem penyimpanan hasil asuhan keperawatan yang telah dilakukan mahasiswa praktik keperawatan. Dosen mengatakan pengeloaan yang baik pada laporan asuhan keperawatan mahasiswa akan membantu dosen dalam mengembangkan aktivitas yang 
komprehensif di wilayah binaan. Selain itu, semua data ataupun aktivitas akan tetap dan terus terekam secara baik.

Berdasarkan identifikasi dan analisis kebutuhan dari partisipan, peneliti melihat perlunya kebutuhan sistem informasi yang mampu menyerap semua data dari masalah kesehatan yang muncul di masyarakat. Data tersebut disusun secara komprehensif menjadi suatu penyajian yang menarik yang mampu mempermudah mahasiswa dalam mengembangkan perencanaan asuhan keperawatan pada klien. Oleh sebab itu, peneliti mencoba mengembangkan SIG sebagai salah satu solusi mengatasi permasalah tersebut. Artikel ini hanya metitikberatkan pada tahapan pengembangan tahapan aplikasi SIG pada penyakit hipertensi sebagai salah satu kasus.

Tahap kedua, peneliti mengembangkan kuesioner hipertensi. Kuesioner ini dikembangkan oleh tim peneliti dengan menggunakan pendekatan model PRECEDEPROCEED. Model ini berorientasi kepada masyarakat karena mampu menilai keberhasilan dan efektivitas program promosi kesehatan yang telah dilakukan oleh institusi pelayanan kesehatan yang ada di Kelurahan $\mathrm{X}$ (Puskesmas). Kuesioner ini telah dilakukan content validity kepada empat ahli dan telah dilakukan uji validitas dan reliabilitas dengan nilai hasil akhir validitas dalam rentang $(0,306-0,867)$ dan reliabilitas dalam rentang $(0,703$ 0,888). Kuesioner ini meliputi lima domain utama dalam proses PRECEDE. Lima domain/fase ini menjadi acuan utama bagi peneliti untuk mengembangkan kuesioner. Ke lima fase tersebut meliputi: diagnosis sosial; diagnosis epidemiologi; diagnosis perilaku dan lingkungan; diagnosis edukasi dan organisasi; dan diagnosis administrasi dan kebijakan Sebagai penjabaran seperti tabel berikut ini:

Tabel 1. Pengembangan Instrumen Penelitian Masalah Hipertensi Berdasarkan Model PRECEDE-PROCEED

\begin{tabular}{|l|l|l|}
\hline $\begin{array}{c}\text { Masalah } \\
\text { kesehatan }\end{array}$ & \multicolumn{1}{|c|}{ Variabel } & \multicolumn{1}{|c|}{ Sub variabel } \\
\hline \multirow{3}{*}{ Hipertensi } & \multirow{2}{*}{ Data Sosial } & Karakteristik Individu \\
\cline { 3 - 3 } & & Data demografi \\
\cline { 2 - 3 } & Data Epidemiologi & Prevalensi data kejadian hipertensi \\
\cline { 3 - 3 } & Perilaku dan Lingkungan & $\begin{array}{l}\text { Perilaku beresiko hipertensi } \\
\text { Perilaku Pencegahan hipertensi }\end{array}$ \\
\cline { 3 - 3 } & & Perilaku Penanganan hipertensi \\
\cline { 2 - 3 } & Pendidikan dan Organisasi & Pengetahuan tentang hipertensi \\
\cline { 3 - 3 } & & Belief/keyakinan terkait hipertensi \\
\cline { 3 - 3 } & & $\begin{array}{l}\text { Dukungan dalam pencegahan dan penanganan } \\
\text { hipertensi }\end{array}$ \\
\cline { 2 - 3 } & Kebijakan dan & Program pelayanan kesehatan terkait hipertensi \\
& Administrasi & \\
\hline
\end{tabular}

Tahapan dilanjutkan dengan penyebaran instrumen penelitian kepada responden penelitian selain dilakukan wawancara kepada kader Posyandu lansia, petugas Puskesmas, tokoh masyarakat terkait program hipertensi yang telah dilaksanakan di wilayah kelurahan X. Wawancara ini menjadi data penunjang dalam penelitian ini dimana dalam SIG data yang bersifat wawancara dikuantitatifkan untuk sesuai indikator yang dibuat dalam SIG.

Peneliti juga melakukan observasi terkait kegiatan Posyandu lansia, kunjungan rumah penderita hipertensi untuk mengetahui perilaku perawatan kesehatan penderita hipertensi. Tujuan utama pada tahapan ini untuk mengidentifikasi masalah-masalah yang muncul yang berhubungan dengan penderita hipertensi dan melakukan identifikasi kebutuhan yang diperlukan untuk pengembangan SIG sesuai dengan kebutuhan. 


\section{B. Perencanaan Desain Aplikasi}

Tahap ini ditekankan pada perencanaan aplikasi yang dibuat. Pengembangan SIG ini mengacu pada tujuan dari kompetensi asuhan keperawatan komunitas yaitu mahasiswa mampu melakukan pengkajian keperawatan komunitas dengan menggunakan pendekatan PRECEDE-PROCEED.

SIG digunakan sebagai suatu strategi untuk menyampaikan secara lebih jelas dan detail data visual yang didapatkan. Selain itu, SIG dirancang dengan menyesuaikan diri terhadap kebutuhan rencana aplikasi yang dibuat baik terkait instrument yang akan digunakan dalam input data maupun peta wilayah cakupan yang mendasar untuk pengembangan SIG. Aplikasi SIG ini diharapkan mampu memberikan informasi yang akurat bagi mahasiswa juga tidak menutup kemungkinan pihak Puskesmas karena SIG mampu memberikan visualisasi yang jelas dan detail tentang kondisi yang dimungkinkan menjadi faktor resiko peningkatan angka hipertensi di area tertentu. Hal ini memberikan landasan yang kokoh bagi perawat ataupun mahasiswa keperawatan dalam melakukan intervensi yang tepat bagi penderita hipertensi karena disesuaikan dengan kebutuhan dan fakta yang ada di lapangan.

\section{Diagram Alir Data}

Diagram 1 menunjukkan bagaimana diagram alir dibuat untuk menjelaskan alur informasi data dalam perencanaan pengembangan SIG pada penderita hipertensi di Kelurahan X.

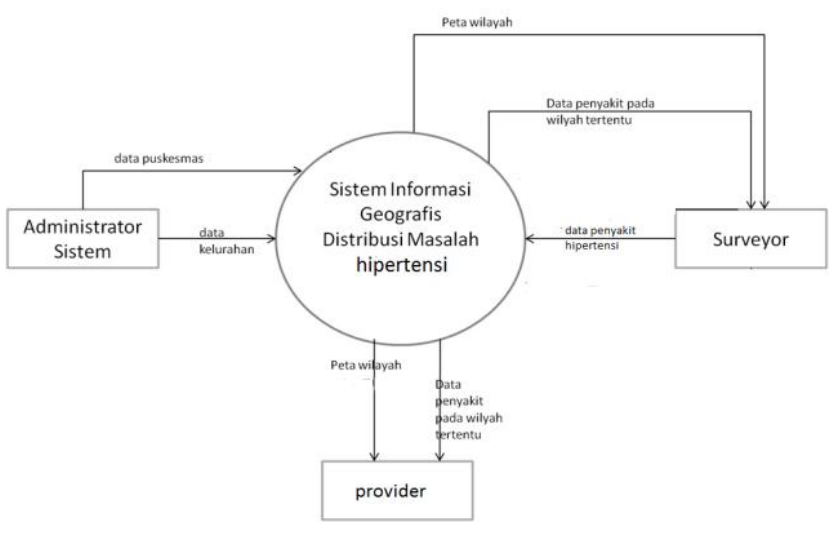

D. Gambaran Aplikasi

Gambar 1 merupakan tampilan pada saat mahasiswa telah masuk ke system SIG, dimana didalam aplikasi tersebut terdapat beberapa menu pilihan yang terkait dengan penderita hipertensi antara lain:

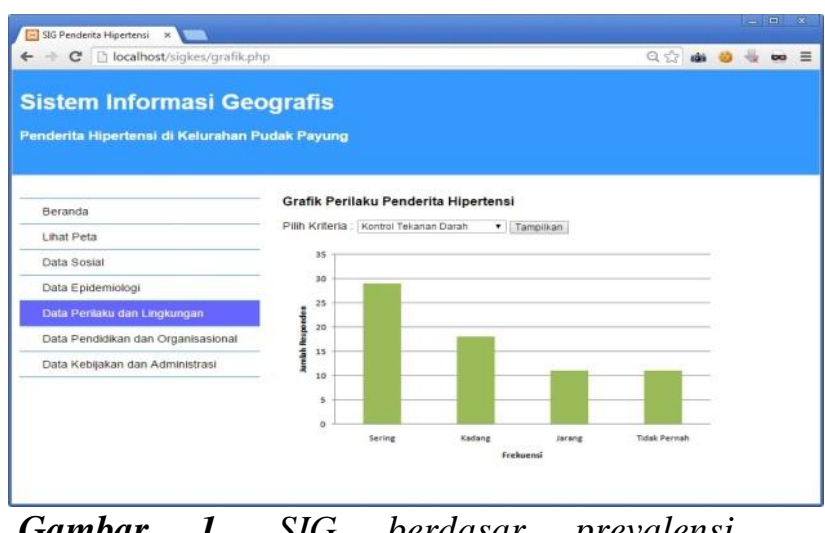

Gambar 1. SIG berdasar prevalensi hipertensi di Kelurahan X

karakteristik penderita; data demografi; data epidemiologi dan lain-lainnya. Dimana di dalam tiap variable terdapat sub variabel yang disesuaikan dengan model PRECEDE-PROCEED.

Gambar 2 merupakan tampilan menu output berbentuk tabel saat pengguna (mahasiswa) mengklik salah satu menu dalam tampilan tersebut. Tampilan disajikan tidka hanya dalam bentuk tabel namun juga dalam bentuk 
peta tematik, maupun grafik disesuaikan dengan instrumen yang digunakan.

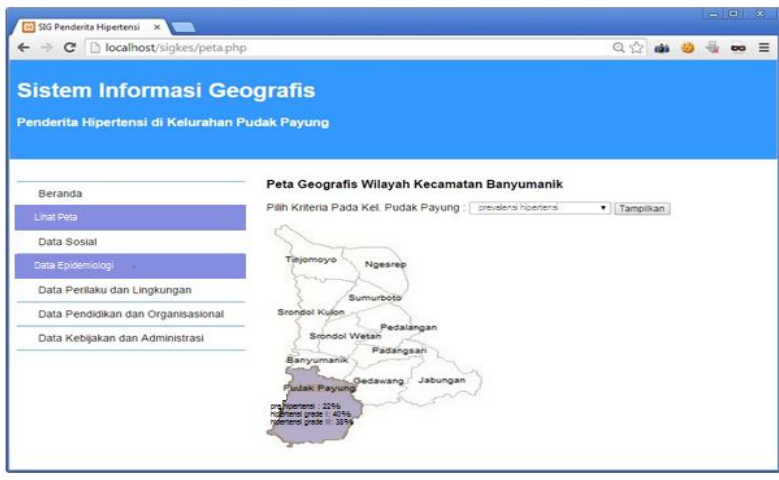

Gambar 2. SIG output grafik data perilaku dan lingkungan berdasar perilaku pengontrolan tekanan darah ke pelayanan kesehatan

\section{PEMBAHASAN}

Penggunaan teknologi geospasial seperti SIG oleh mahasiswa saat ini meningkat di berbagai universitas di seluruh dunia khususnya di negara maju. Penggunaan SIG mampu meningkatkan dan mengembangkan kemampuan berpikir kritis dan spasial (Kolvoord, Uttal, \& Meadow, 2011). SIG memberikan stimulasi dalam pembelajaran terkait lokasi ataupun area terjadinya masalah kesehatan khususnya hipertensi, faktor risiko yang kemungkinan berkorelasi dengan masalah hipertensi yang ada di daerah tersebut dan akses ke pelayanan kesehatan bagi penderita hipertensi. Hal tersebut selaras dengan penyataan dari Nykiforuk dan Flaman (2011) yang menyatakan terdapat empat bidang utama yang menjadi fokus dalam penggunaan SIG yaitu: survei penyakit, analisis risiko, akses kesehatan dan perencanaan dan profil komunitas.

SIG juga mampu menyajikan secara detail terkait aksesibilitas pelayanan kesehatan yang mampu diakses oleh masyarakat terdekat saat mengalami kejadian darurat karena hipertensi yang diidap penderita misalnya: stroke dan lainlain. Melalui SIG, mahasiswa belajar untuk menganalisis dan memprediksikan risiko ataupun potensial masalah kesehatan yang akan terjadi di masa datang dan mengembangkan intervensi yang bersifat prevensi baik primer, sekunder dan tersier.

Kegunaan lain dari penggunaan teknologi SIG ini dapat memotivasi dan mendorong mahasiwa dalam menyelidiki topik yang mempunyai relevansi dengan kompetensi yang harus dikuasai. Simulasi melalui SIG mampu secara efektif untuk mengembangkan kompetensi dalam penilaian, keterampilan klinis, dan aplikasi kritis berpikir (Beyea, von Reyn, \& Slattery, 2007). Selain itu, penggunaan teknologi ini memfasilitasi pola pembelajaran yang berbasis Student Centered Learning (SCL) yang telah dikembangkan di beberapa universitas di Indonesia khususnya di bidang keperawatan.

Mahasiswa sebelumnya telah diperkenalkan dasar-dasar pengetahuan untuk menilai kesehatan masyarakat melalui model PRECEDE-PROCEED di dalam perkuliahan. Contohnya adalah data terkait sosio demografi, masalah kesehatan/penyakit, juga terkait faktorfaktor yang berisiko meningkatkan atau menurunkan masalah kesehatan/penyakit tersebut, bagaimana kebijakan terkait masalah kesehatan di Indonesia dan strategi pendidikan kesehatan. Selain itu, mahasiswa telah belajar tentang bagaimana data dapat diperoleh, bagaimana menafsirkannya, dan bagaimana menerapkannya untuk memecahkan masalah melalui pendekatan asuhan keperawatan.

Penerapan konsep yang didapatkan di perkuliahan seringkali mengalami kendala di lapangan terkait kerumitan khususnya proses tabulasi data dan penyajian data yang integratif. Fenomena 
saat ini yang berkembang di beberapa program keperawatan di jenjang universitas khususnya di bidang keperawatan komunitas, mahasiswa yang sedang melakukan praktik keperawatan komunitas saat melakukan penilaian berbasis populasi menggunakan tabulasi data dengan cara yang sederhana baik tabulasi data dan penyajian data pengkajian dengan cara manual ataupun dengan bantuan computer missal menggunakan program Microsoft excell. Namun, kedua cara tersebut tidak dapat memberikan gambaran secara menyeluruh secara visual. Sangat sedikit sekali mahasiswa keperawatan yang menyajikan data pengkajian dengan menggunakan peta area yang dibina sehingga dimungkinkan adanya ketidaksinkronan intervensi yang akan dilakukan. Misal: mahasiswa memprediksikan bahwa muncul risiko peningkatan jumlah penderita stroke di wilayah binaan. Kemudian mahasiswa menyusun intervensi terkait prevensi primer terkait penggunaan fasilitas kesehatan yaitu Puskesmas. Namun kesederhanaan metode yang digunakan membuat mahasiswa tidak memperhitungkan aksesibilitas pelayanan Puskesmas bagi beberapa pasien yang tinggal di daerah yang jauh dari Puskesmas.

Kondisi ini sebenarnya dapat diminimalkan, adanya teknologi SIG yang mampu memberikan informasi pelayanan kesehatan yang terdekat yang dapat diakses oleh penderita hipertensi secara tepat karena telah tervisualisasi secara jelas dalam peta. SIG merupakan teknologi dapat digunakan untuk menemukan layanan kesehatan bagi masyarakat yang membutuhkan, dalam kasus ini adalah penderita hipertensi yang dengan mudah mengakses pelayanan kesehatan terdekat. SIG dirancang untuk membantu, biaya yang efektif, dan berkelanjutan dengan menggunakan sumber daya yang ada komunitas terdekat (Carlson, York, \& Primomo, 2011) khususnya perawat ataupun pengguna pelayanan kesehatan dalam pemberian pelayanan kesehatan.

Praktik keperawatan komunitas juga merupakan praktik yang bersifat kolaboratif dan partnership dengan lembaga yang ada di lingkungan tersebut. Hasil pengkajian dari mahasiswa pada umumnya disajikan pada musyawarah masyarakat dimana semua komponen masyarakat hadir dalam pertemuan tersebut. Penggunaan SIG, akan memberikan daya tarik tersendiri dalam penyajian data dan memberikan kesempatan pada mahasiwa untuk lebih semakin kompeten dalam mengintegrasikan slide Power Point dan gambar digital dari wilayah layanan ke dalam presentasi tersebut. Penggunaan peta GIS akan memberikan gambaran yang komprehensif dan integratif terkait masalah kesehatan yang dipresentasikan dan dan meningkatkan pemahaman tentang bagaimana berbagai sumber data terkait dan mempengaruhi satu sama lain (Riner, Cunningham, \& Johnson, 2004).

\section{Implikasi keperawatan}

Keperawatan komunitas salah satunya menekankan pada aspek lingkungan/komunitas sebagai faktor yang mempengaruhi masalah kesehatan. Mahasiswa sebagai calon perawat harus dibekali dengan kemampuan menganalisa karakteristik lingkungan/komunitas yang menjadi area binaan yang berpotensi ataupun berisiko meningkatkan kesehatan pasien. SIG merupakan alat bantu dalam mengembangkan kemampuan analisis komunitas/lingkungan dengan memberikan data visual yang detail sehingga mahasiswa mampu mengintegrasikan semua sumber daya yang ada di lingkungan dan komunitas untuk 
mengembangkan intervensi yang komprehensif (Riner, Cunningham, \& Johnson, 2004).

Selain itu, SIG akan meningkatkan pengambilan keputusan dalam memecahkan masalah kesehatan secara komprehensif (Kaneko, Takano \& Nakamura, 2003). Mahasiswa menjadi calon pemegang keputusan dalam tim kesehatan dimana mahasiswa dituntut memberikan keputusan yang tepat dalam peningkatan kesehatan masyarakat secara keseluruhan baik individu, kelompok maupun masyarakat. Perawat komunitas merupakan bagian dari anggota tim kesehatan sehingga dengan kemampuan yang diasah sejak dini di bangku perkuliahan, mahasiswa akan terasah dalam melakukan kolaborasi dengan tim lain.

Implikasi lain terkait penggunaan SIG adalah di area penelitian. Asuhan keperawatan merupakan salah satu metode dalam penelitian ilmiah. Mahasiwa keperawatan selama masa perkuliahan telah mendalami prinsip penelitian dalam proses pembelajaran dengan melaksanakan asuhan keperawatan kepada pasien baik pendekatan secara individu, kelompok ataupun masyarakat. Namun kemajuan penelitian ilmiah harus terus dioptimalkan dengan memberikan kesempatan dalam penggunaan suatu metodologi penelitian yang baru (Davern \& Chen, 2010).

Khususnya keperawatan di Indonesia, penggunaan SIG sebagai suatu metodologi penelitian belum pernah ada. Padahal berdasarkan riset yang telah dilakukan pada penelitian sebelumnya dibuktikan bahwa SIG telah terbukti menjadi alat yang handal yang dapat berhasil diintegrasikan ke dalam penelitian yang difokuskan pada dampak lingkungan terhadap hasil kesehatan (Andrews, 2006).

Beberapa penelitian keperawatan menyarankan untuk mengembangkan SIG dalam penelitian keperawatan berbasis masyarakat/komunitas (Moss \& Schell, 2004). Data dari SIG dapat menjadi hasil dari penelitian deskriptif. Dimana dari hasil data tersebut dapat dikembangkan baik pengujian hipotesis ataupun hanya bersifat exploratif ataupun studi kasus.

\section{KESIMPULAN DAN SARAN}

Sistem Informasi Geografis (SIG) merupakan teknologi informasi yang relatif asing digunakan dalam bidang keperawatan khususnya keperawatan komunitas di Indonesia. Pada kenyataannya banyak manfaat penggunaan SIG yang dapat diaplikasikan dalam keperawatan komunitas terkait visualisasi penyebaran masalah kesehatan yang terjadi di masyarakat dan faktor risiko yang menyertainya. Berdasarkan hal tersebut maka perlu adanya pengembangan kurikulum di keperawatan komunitas khususnya di tingkat magister, spesialis ataupun jenjang doctoral yang mampu mendorong pencapaian kompetensi mahasiswa dalam penerapan teknologi informasi terkini yang menunjang pemberian asuhan keperawatan komunitas. Selain itu, perlu dibuka peluang yang selebar-lebarnya bagi mahasiswa yang tertarik dalam aplikasi teknologi geospasial dalam area penelitian, sehingga diharapkan lebih meningkatkan kemampuan mahasiswa sebagai calon perawat dalam mengembangkan keilmuaannya.

\section{UCAPAN TERIMA KASIH}

Peneliti mengucapkan terimakasih kepada DIKTI sebagai sponsor dalam penelitian ini. Penelitian ini merupakan bagian dari hibah penelitian dengan skema hibah bersaing. 


\section{DAFTAR PUSTAKA}

Andrews, G. J. (2006). Geographies of health in nursing. Health \& Place, 12(1), 110-118.

Beyea, S., von Reyn, L., \& Slattery, M. (2007). A nurse residency program for competency development using human patient simulation. Journal for Nurses in Staff Development, 23(2), 77-82.

Caley, L. M. (2004). Using geographic information systems to design population-based interventions. Public Health Nursing, 21(6), 547-554.

Carlson, T., York, S., \& Primomo, J. (2011). The utilization of geographic information systems to create a site selection strategy to disseminate an older adult fall prevention program. The Social Science Journal, 48(1), 159-174.

Courtney, K. L. (2005). Visualizing nursing workforce distribution: policy evaluation using geographic information systems. International journal of medical informatics, 74(11), 980-988.

Davern, M. T., \& Chen, X. (2010). Piloting the geographic information system (GIS) methodology as an analytic tool for subjective wellbeing research. Applied Research in Quality of Life, 5(2), 105-119.

Faruque, F., Hewlett, P. O., Wyatt, S., Wilson, K., Lofton, S., Frate, D., \& Gunn, J. (2004). Geospatial information technology: an adjunct to service-based outreach and education. Journal of Nursing Education, 43(2), 88-91.

Green, L. \& Kreuter, M. (1991). Health promotion planning. (2nd ed.). Mountain View: Mayfield Publishing Co.

Kaneko, Y., Takano, T., \& Nakamura, K. (2003). Visual localisation of community health needs to rational decision-making in public health services. Health \& Place, 9(3), 241251.

Kolvoord, A., Uttal, D. H., \& Meadow, N. G. (2011). Using video case studies to assess the impact of the use of GIS on secondary students' spatial thinking skills Robert. Procedia-Social and Behavioral Sciences, 21, 372-379.

Li, F., Harmer, P., Cardinal, B. J., Bosworth, M., \& Johnson-Shelton, D. (2009). Obesity and the built environment: does the density of neighborhood fast-food outlets matter?. American Journal of Health Promotion, 23(3), 203-209.

Laosuwan, T. (2012). Online web GISbased services for spatial data and sharing of leptospirosis epidemiology information; Development of pilot project in Mahasarakham province Thailand. International Journal of Geomatics and Geosciences, 3(1), 121-133.

Moss, M., Schell, M. (2004). GISc A scientific framework and methodological tool for nursing research. Advances in Nursing Science 27(2), 150-159.

Nykiforuk, C. I. J., \& Flaman, L. M. (2011). Geographic Information Systems (GIS) for health promotion and public health: a review. Health Promotion Practice, 12(1),63-73.

Riner, M. E., Cunningham, C., \& Johnson, A. (2004). Public health education and practice using geographic information system technology. Public health nursing, 21(1), 57-65.

Yamashita, T., \& Kunkel, S. R. (2010). The association between heart disease mortality and geographic access to hospitals: county level comparisons in Ohio, USA. Social Science \& Medicine, 70(8), 1211-1218. 